\title{
LTP or LTD? Modeling the Influence of Stress on Synaptic Plasticity
}

\author{
(1)Achim Peters, ${ }^{1}$ - ${ }^{-}$Cordula Reisch, ${ }^{2}$ and Dirk Langemann ${ }^{2}$
}

DOI:http://dx.doi.org/10.1523/ENEURO.0242-17.2018

${ }^{1}$ Medical Clinic 1, Endocrinology and Diabetes, University of Luebeck, Luebeck D-23538, Germany and ${ }^{2}$ Institut Computational Mathematics, Technical University Braunschweig, Braunschweig D-38106, Germany

\begin{abstract}
In cognitive memory, long-term potentiation (LTP) has been shown to occur when presynaptic and postsynaptic activities are highly correlated and glucocorticoid concentrations are in an optimal (i.e., low normal) range. In all other conditions, LTP is attenuated or even long-term depression (LTD) occurs. In this paper, we focus on NMDA receptor (NMDA-R)-dependent LTP and LTD, two processes involving various molecular mechanisms. To understand which of these mechanisms are indispensable for explaining the experimental evidence reported in the literature, we here propose a parsimonious model of NMDA-R-dependent synaptic plasticity. Central to this model are two processes. First, AMPA receptor-subunit trafficking; and second, glucocorticoid-dependent modifications of the brain-derived neurotrophic factor (BDNF)-receptor system. In 2008, we have published a core model, which contained the first process, while in the current paper we present an extended model, which also includes the second process. Using the extended model, we could show that stress attenuates LTP, while it enhances LTD. These simulation results are in agreement with experimental findings from other labs. In 2013, surprising experimental evidence showed that the GluA1 C-tail is unnecessary for LTP. When using our core model in its original form, our simulations already predicted that there would be no requirement for the GluA1 C-tail for LTP, allowing to eliminate a redundant mechanism from our model. In summary, we present a mathematical model that displays reduced complexity and is useful for explaining when and how LTP or LTD occurs at synapses during cognitive memory formation.
\end{abstract}

Key words: cognitive memory; glucocorticoids; long-term depression; long-term potentiation; mathematical model; stress

\section{Significance Statement}

Synaptic plasticity is a complex process. For the description of biological processes, the best mathematical model is characterized by low complexity and high accuracy. Here, we present a "low-complexity" model of synaptic plasticity that predicts the available experimental data with "high accuracy." Among other things, one can use the model to explain how stress affects the occurrence of NMDA-R-dependent LTP and LTD.

\section{Introduction}

For decades, stress has been reported to affect memory formation (de Kloet et al., 1998; Joëls, 2006; Popoli et al., 2011). Stress-induced rises in glucocorticoid con-

Received July 10, 2017; accepted January 21, 2018; First published February 16, 2018.

The authors declare no competing financial interests.

Author contributions: A.P. and D.L. designed research; A.P., C.R., and D.L. performed research; A.P., C.R., and D.L. analyzed data; A.P. and D.L. wrote the paper.

Correspondence should be addressed to Achim Peters, Medical Clinic 1, centrations have been shown to exert differential effects on cognitive and emotional memories (Maggio and Segal, 2012). While stress typically impairs cognitive memories, it may enhance emotional memories as is the case of fear

Endocrinology and Diabetes, University of Luebeck, Ratzeburger Allee 160, Luebeck D-23538, Germany, E-mail: achim.peters@uksh.de.

DOI:http://dx.doi.org/10.1523/ENEURO.0242-17.2018 Copyright (C) 2018 Peters et al.

This is an open-access article distributed under the terms of the Creative Commons Attribution 4.0 International license, which permits unrestricted use, distribution and reproduction in any medium provided that the original work is properly attributed. 
memory (Quirarte et al., 1997). The current paper focuses on the effect of glucocorticoids on cognitive memories. Particularly, we will focus on NMDA receptor (NMDA-R)dependent synaptic potentiation (LTP) and depression (LTD), two forms of activity-dependent long-term changes in synaptic efficacy that have been extensively studied in brain slice cultures. Glucocorticoids affect NMDA-dependent synaptic plasticity, which typically occurs in the dorsal hippocampus. Here as well as in other brain regions, glucocorticoids affect intracellular mineralocorticoid receptors (MRs) and glucocorticoid receptors (GRs). MRs show a high affinity to glucocorticoids, while GRs show low affinity (Arriza et al., 1988). There is experimental evidence that in the dorsal hippocampus stress reduces long-term potentiation (LTP), while it enhances long-term depression (LTD; Maggio and Segal, 2007, 2009).

A key link between glucocorticoid actions and LTP probability is the signaling of brain-derived neurotrophic factor (BDNF): particularly the production of its highaffinity receptors TrkB and its low-affinity receptors $\mathrm{p} 75$. TrkB receptor signaling facilitates LTP (Minichiello et al., 1999; Zhang and Poo, 2002), while p75 receptor signaling facilitates LTD (Rösch et al., 2005; Woo et al., 2005). Glucocorticoid-activated MR and GR receptors control the production rates of TrkB and $p 75$ receptors. A series of elegant experiments manipulating glucocorticoid concentrations has demonstrated that at low glucocorticoid concentrations MRs enhance TrkB-production and LTP (Stranahan et al., 2008, 2010, 2011), while at high glucocorticoid concentrations GRs suppress TrkB-production and LTP (Wosiski-Kuhn et al., 2014). In this way, TrkB production is maximal at low (normal) glucocorticoid concentration and minimal in the absence of glucocorticoids or at high glucocorticoids concentration.

In addition to stress, a second factor also determines the induction and maintenance of LTP and LTD. This is correlated activity between the presynaptic and postsynaptic neuron. For LTP induction both pre- and postsynaptic neurons need to be active at the same time because the postsynaptic neuron must be depolarized when glutamate is released from the presynaptic bouton to fully relieve the $\mathrm{Mg}^{++}$block of NMDA-Rs. There is extensive evidence that modest activation of NMDA-Rs leading to modest increases in postsynaptic calcium is optimal for triggering LTD, while a much stronger activation of NMDA-Rs leading to much greater increases in postsynaptic calcium, is required to trigger LTP (Luscher and Malenka, 2012; Miyashita et al., 2012). Since the direction of synaptic plasticity depends on the timing between the presynaptic and postsynaptic spikes, this phenomenon has been called "spike-timing-dependent plasticity" (Bi and Poo, 2001). If a presynaptic spike is repetitively elicited slightly before the postsynaptic neuron is fired, the excitatory postsynaptic potential precedes the backpropagating action potential, and such repetitive "pre-post" action potential firing can generate LTP. Conversely, when the backpropagating action potential is repetitively elicited before the presynaptic spike, "post-pre" firing, LTD is often observed. Thus, NMDA-Rs, and in some cases the voltagedependent calcium channels (VDCCs), may function as co- incidence detectors (Luscher and Malenka, 2012; Miyashita et al., 2012).

Both factors, the effects of glucocorticoids (indicating the presence of stress) and the effects of NMDA-Rs (indicating correlated pre-/postsynaptic activity) converge in one common point. This is the interaction between the ligand BDNF and its TrkB receptor. If there is coincidental activity of the pre- and postsynaptic neuron, proBDNF is converted to mature BDNF (mBDNF), and in this way the concentrations of mBDNF in the synaptic cleft rise. If glucocorticoid concentrations are low (normal), the number of postsynaptically expressed TrkB receptors is maximal. Thus, if many BDNF molecules can interact with a large number of TrkB receptors, LTP is promoted.

In the current paper, we present a mathematical model that uses differential equations for describing how stress affects the BDNF/TrkB-receptor system, and how the BDNF/TrkB-receptor system influences AMPA receptor trafficking (Fig. 1). Our model is based on a "core model" on AMPA receptor trafficking that we had published earlier (Langemann et al., 2008). Here, we use an "extended model" which adds the stress-dependent processes that modify the BDNF/TrkB-receptor system. Using experimental findings from another lab (Maggio and Segal, $2007,2009)$, we show that our extended model allows to predict how stress influences the induction and maintenance of LTP or LTD in cognitive memory formation.

\section{Materials and Methods}

The plasticity model discussed in (Langemann et al., 2008) is shortly presented and extended by a modeling step regarding the stress level and the coincidence of preand postsynaptic activity. The new modeling step describes mechanisms which lie causally before the core plasticity model.

\section{Code accessibility}

The code is accessible as Extended data.

\section{Biochemical reaction kinetics}

Synaptic plasticity depends on the amount of activated $\left(R_{S}^{\prime}\right)$ and nonactivated $\left(R_{S}\right)$ short tail AMPA subunits (Shi et al., 2001). NEM-sensitive factor (NSF) activates shorttail AMPA subunits (Nishimune et al., 1998). This reaction can be written as

$$
R_{S}+N S F \stackrel{k_{0}, k_{4}}{\leftrightarrow} R_{S}^{\prime},
$$

where $k_{0}$ and $k_{4}$ are nonlinear reaction parameters. Therein, $k_{o}$ depends on the amount of activated $\mathrm{R}_{\mathrm{s}} \mathrm{R}_{\mathrm{s}}$ homomers, and $k_{4}$ is influenced by nonactivated $R_{S} R_{L}$ heteromers. The polymerizations, leading to homomeric and heteromeric AMPA units (Esteban, 2003), are

$$
2 R_{S}^{\prime}{ }_{S}^{k_{1}, k_{2}} \leftrightarrow R_{S}^{\prime} R_{S}^{\prime},
$$

and

$$
R_{S}+R_{L} \stackrel{k_{5}, k_{6}}{\leftrightarrow} R_{S} R_{L}
$$




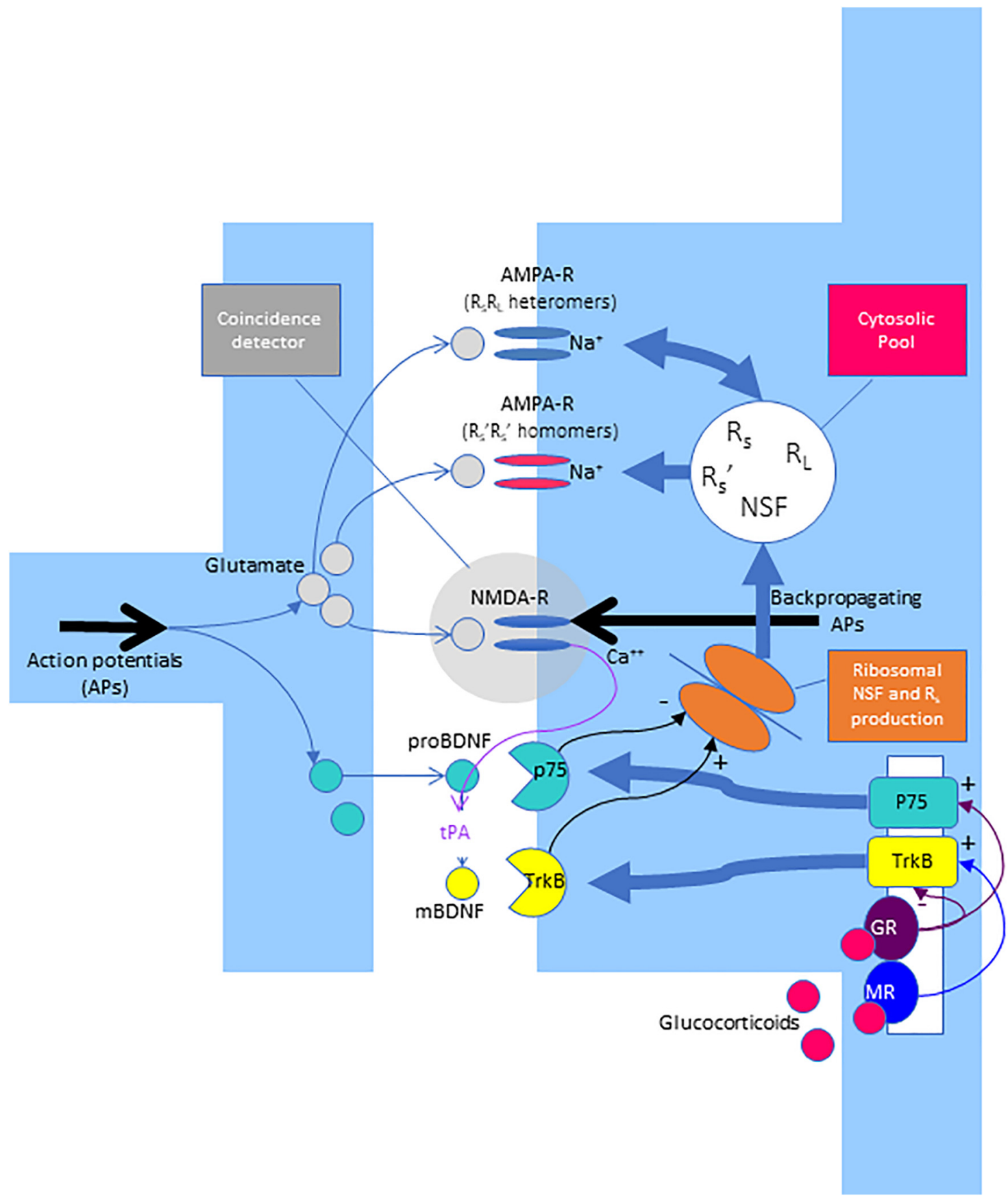

Figure 1. Modeling the glucocorticoid dependency of NMDA-R-dependent LTP and LTD. The core model, published earlier (Langemann et al., 2008), describes the trafficking of AMPA receptor subunits. In brief, a cytosolic pool consists of short-tailed AMPA receptor subunits $\left(R_{S}\right)$, long-tailed AMPA receptor subunits $\left(R_{L}\right)$, and NSF. $R_{S}$ consist of the short-tailed AMPA receptor subunits GluA2 or GluA3; $R_{L}$ consist of GluA1 or GluA4. In case of high numbers of $R_{S}$ and NSF molecules, the probability of NSF binding to $R_{S}$ is high, and in this way, the formation of activated $R_{S}^{\prime}$ is promoted. Activated $R_{S}^{\prime}$ form $R_{S}^{\prime} R_{S}^{\prime}$ homomers, which in turn endorse further activation of existing $R_{S}$ into $R_{S}$. In case of low numbers of $R_{S}$ and NSF molecules, nonactivated $R_{S}$ prevail. Nonactivated $R_{S}$ promote the formation of $R_{S} R_{L}$ heteromers, which in turn endorse deactivation of existing $R_{S}^{\prime}$ into $R_{S}$. Thus, there is a double positive feedback loop. First, the occurrence of AMPA receptor homomers increases numbers of R's, which in turn endorses the formation of more AMPA receptor homomers. Second, the occurrence of AMPA receptor heteromers increases the number of $R_{S}$, which in turn endorses the formation of more AMPA receptor heteromers. The extended model, as presented in the current article, describes how correlated pre/postsynaptic activity and glucocorticoid concentrations modify ribosomal $\mathrm{R}_{\mathrm{S}}$ and NSF production. Incoming action potentials elicit glutamate release. Glutamate can only activate NMDA-Rs if the postsynaptic cell is coincidentally depolarized by backpropagating action potentials. Therefore, the NMDA-R functions as a coincidence detector. On NMDA-R activation, tPA is released into the synaptic cleft, thereby converting proBDNF into mBDNF. Hence, high concentrations of mBDNF indicate highly correlated activity between the pre- and the postsynaptic neuron. mBDNF primarily binds to TrkB receptors, while proBDNF primarily binds to p75 receptors. The numbers of TrkB and p75 receptors expressed on the postsynaptic density depend on glucocorticoid 
continued

concentrations. Glucocorticoids bind with high affinity to MRs and with low affinity to GRs. Low (normal) glucocorticoid concentrations promote (via MRs) the production of TrkB receptors, while high glucocorticoid concentrations (via GRs) inhibit TrkB production and favor p75 production. Hence, a large number of TrkB receptors on the postsynaptic density indicates low (normal) glucocorticoid concentrations. On interaction between mBDNF and its TrkB receptors, ribosomal NSF and $\mathrm{R}_{\mathrm{S}}$ production rates are enhanced; on interaction between proBDNF and its p75 receptors, ribosomal NSF and $\mathrm{R}_{\mathrm{S}}$ production rates are suppressed. Consequently, the interaction between correlated pre/postsynaptic activity and glucocorticoid concentrations determine the proportional distribution of $R_{S}, R_{L}$, and NSF in the cytosolic pool. In turn, the proportional distribution of $R_{S}, R_{L}$, and NSF in the cytosolic pool determines the number of AMPA receptor homomers in the postsynaptic density: an increased number of AMPA receptor homomers indicates LTP, a decreased number of AMPA receptor homomers indicates LTD.

with constant reaction rates $k_{1}, k_{2}, k_{5}$, and $k_{6}$ for both directions of the bidirectional polymerization reactions. As mentioned in (Langemann et al., 2008), not only dimers but also tetramers take part in the reactions. The occurrence of tetramers depends on the concentration of activated shorttail units. Therefore, the production of tetramers can be seen as a secondary reaction. We regard the occurrence of dimeric polymers as qualitative representative for the presence of realistic tetrameric homomers and heteromers.

The polymerization influences the activation of $R_{S}$ (Langemann et al., 2008). To be more precise, the activation reaction parameter $k_{0}$ depends nonlinearly on the concentration of activated homomers $\mathrm{R}_{S} \mathrm{R}_{\mathrm{S}}$ and the deactivation reaction parameter $k_{4}$ depends nonlinearly on the concentration of nonactivated heteromers $R_{S} R_{L}$. The activated homomeric and nonactivated heteromeric dimers depend on activated or, respectively, nonactivated short-tailed subunits. As a result, we get nonlinear dependencies $k_{o}\left(\left[\mathrm{R}_{\mathrm{S}}\right]\right)$ and $k_{4}\left(\left[\mathrm{R}_{\mathrm{S}}\right]\right)$, and very simple examples of them are shown in Figure 2.

Altogether, we get reaction kinetics for the main components $R_{S}, R_{S}^{\prime}$, and NSF by

$$
\begin{gathered}
{[N S F]=p_{N S F}-z_{N S F}[N S F]-k_{0}\left(R^{\prime}\right) \cdot\left[R_{S}\right][N S F]+k_{4}\left(R_{S}\right) \cdot} \\
{\left[R^{\prime}{ }_{S}\right],} \\
{\left[\dot{R}_{S}\right]=p_{R_{S}}-z_{R_{S}}\left[R_{S}\right]-k_{0}\left(R^{\prime}{ }_{S}\right) \cdot\left[R_{S}\right][N S F]+k_{4}\left(R_{S}\right) \cdot\left[R^{\prime}{ }_{S}\right],} \\
{\left[\dot{R}_{S}^{\prime}\right]=-z_{R^{\prime}}\left[R^{\prime}{ }_{S}\right]+k_{0}\left(R^{\prime}{ }_{S}\right) \cdot\left[R_{S}\right]\left[N S F-k_{4}\left(R_{S}\right) \cdot\left[R^{\prime}{ }_{S}\right],\right.}
\end{gathered}
$$

where $p_{\#}$ are production rates and $z_{\#}$ are decay parameters of substance \#.

The ribosomal protein production rates of NSF and $R_{s}$ are increased by TrkB receptors (Minichiello et al., 1999; Narisawa-Saito et al., 1999; Zhang and Poo, 2002) and

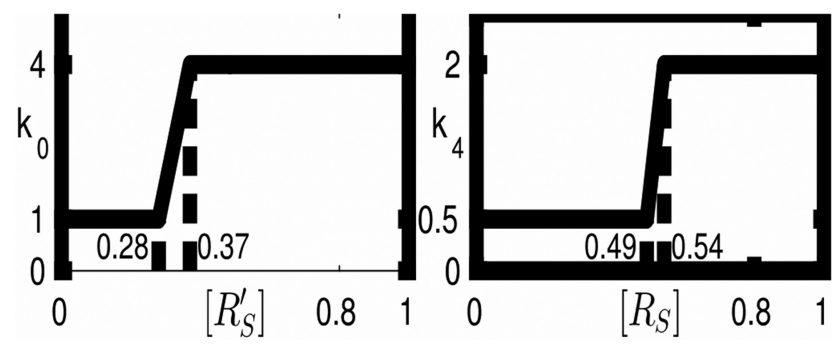

Figure 2. Nonlinear kinetics. Left, $\mathrm{k}_{0}$ depends on activated shorttailed AMPA receptor subunits ( $\left.\mathrm{R}_{\mathrm{S}}^{\prime}\right)$. Right, $\mathrm{k}_{4}$ depends on nonactivated short-tailed AMPA receptor subunits $\left(R_{S}\right)$. decreased by p75 (Rösch et al., 2005; Woo et al., 2005). These numbers of membrane TrkB and p75 receptors depend on cortisol concentrations and thus on stress. This is because glucocorticoid-activated MR and GR receptors control the production rates of TrkB and p75 receptors. In detail, MR enhances TrkB receptor production (Schaaf et al., 1997); GR counteracts TrkB receptor production (Schaaf et al., 1997) and promotes the production of p75 receptors (Shi and Mocchetti, 2000).

We distinguish two main factors for inducing and maintaining LTP or LTD: first, correlated/noncorrelated pre-/ postsynaptic activity and, second, the presence/absence of stress. The first concerns the coincidence of the incoming action potentials, i.e., the signal $s(t)$, with backpropagating action potentials. The incoming signal causes a production of activated calmodulin-dependent protein kinase II (CaMKII) ([CaMKII]) as in

$$
\left[\text { CaḾKIII] }=b_{\text {CaMKIS }}(t)-z_{\text {CaMKII }}[\text { CaMKII] },\right.
$$

where $b_{\text {CaMKII }}$ describes the influence of glutamate on the production of CaMKII. Besides, glutamate triggers a release of tissue plasminogen activator ([TPA]) into the synaptic cleft as in

$$
[t \dot{P} A]=\sigma s(t)-z_{t P A}[t P A],
$$

where $\sigma$ is a parameter for the coincidence of pre/postsynaptic activity (pre: glutamate release/post: backpropagating action potentials; Gualandris et al., 1996). The NMDA-R serves as a coincidence detector, as it allows $\mathrm{Ca}^{++}$influx only during correlated activation of both preand postsynaptic cells (Miyashita et al., 2012). If there is highly correlated pre/postsynaptic activity, $\sigma$ is large; otherwise, $\sigma$ is small or zero. tPA influences BDNF. In detail, tPA, by activating the extracellular protease plasmin, converts the precursor proBDNF to the mBDNF (Pang et al., 2004). The reaction can be described as

$$
\text { proBDNF }+t P A \stackrel{k_{8}, k_{9}}{\leftrightarrow} m B D N F,
$$

where $k_{8}$ is a parameter for the forming of mBDNF and $k_{9}$ is a parameter for the forming proBDNF.

Stress increases the cortisol concentrations [C]. Cortisol binds to intracellular MRs with high affinity and to GRs with low affinity (Arriza et al., 1988). We describe these reactions with Michaelis-Menten kinetics 


$$
[M R]=\frac{[C]}{[C]+M_{M R}}, \quad[G R]=\frac{[C]}{[C]+M_{G R}},
$$

where $M_{\mathrm{MR}}$ and $M_{\mathrm{GR}}$ are Michaelis constants for saturated production of MR and GR, respectively. The preferred binding of cortisol with MR is expressed by $M_{\mathrm{MR}} \ll M_{\mathrm{GR}}$.

Activated MR and GR regulate the expression of TrkB and $p 75$ receptors. MR has a positive effect on TrkB expression; GR has a positive effect on the expression of p75 and a negative effect on TrkB (Schaaf et al., 1997; Shi and Mocchetti, 2000). Hence, the amount of TrkB and p75 receptors depend on the stress level. ProBDNF binds to p75 with a high affinity (Lee et al., 2001). In contrast, mBDNF binds to TrkB with high affinity and to p75 with a low affinity (Huang and Reichardt, 2003).

Activated proBDNF $\left[p B D N F_{a c t}\right]$ and $\mathrm{mBDNF}\left[m B D N F_{a c t}\right]$ influence the production rates of NSF and $R_{S}$. The production rate increases with active mBDNF (Minichiello et al., 1999; Narisawa-Saito et al., 1999; Zhang and Poo, 2002) and decreases with proBDNF (Rösch et al., 2005; Woo et al., 2005) like

$$
\dot{a}=b_{a}\left(\left[p B D N F_{a c t}\right]-\left[m B D N F_{a c t}\right]\right)-z_{a} a,
$$

where $b_{a}$ is a parameter for the influence of the neurotrophic factor and $z_{\mathrm{a}}$ is the linear decay rate. This is the point, where the new mechanisms docks onto the core model of (Langemann et al., 2008).

In the same way, as in Langemann et al. (2008), we describe the signal transmission dependent on the homomeric and heteromeric AMPA units in the membrane. Therefore, we use catalytic reactions for the transfer of $R_{S} R_{L}$ in the membrane

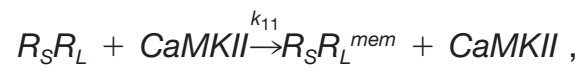

and for the opposed reaction with decomposition

$$
R_{S} R_{L}^{\text {mem }}+\text { Glut } \stackrel{k_{12}}{\rightarrow} R_{S}+R_{L}+\text { Glut } .
$$

Furthermore, heteromeric units vanish from the membrane

$$
R_{S} R_{L} \stackrel{k_{12}}{\rightarrow} R_{S} R_{L} .
$$

The amount of activated homomeric AMPA units in the membrane is proportional to the amount of activated homomeric units,

$$
\left[R^{\prime}{ }_{S}{ }^{\prime}{ }_{S}\right] \propto\left[R^{\prime}{ }_{S} R^{\prime}{ }^{\mathrm{mem}}\right] .
$$

Based on these reaction, the transmitted signal is modeled by

$$
s_{i n}(t)=2\left(\left[R^{\prime}{ }_{S} R_{S}^{\prime m e m}\right]+\left[R_{S} R_{L}{ }^{m e m}\right]\right) s(t) .
$$

\section{Parameter choice}

Besides the time scale, which is realistic, the concentrations are normalized. Except from a few parameters, the parameters are normalized to 1. Exceptions are the
Michalis constants $M_{\mathrm{MR}}=0.0001$ and $M_{\mathrm{GR}}=5$. The sensitivity of the production rate of NSF depending on TrkB is $u_{\mathrm{NSF}}=3$ and therefore higher than the other sensitivities. The decay of tPA and proBDNF is slower than the other reactions, $\mathrm{z}_{\mathrm{tPA}}=0.5$ and $\mathrm{z}_{\text {proBDNF }}=0.1$. In contrast, the decay of active TrkB and active p75 are faster, $z_{\text {actTrkB }}=2$ and $z_{\text {actp } 75}=2$. BDNF, active TrkB and tPA have a higher production rate with $p_{\mathrm{BDNF}}=10, \mathrm{p}_{\mathrm{actTrkB}}=$ 10 and $p_{\mathrm{tPA}}=2$. The used parameter set is simple enough, and the qualitative behavior of the system of differential equations do not depend on a single chosen parameter or its variation.

\section{Model properties}

As discussed in Langemann et al. (2008), the rates of change $[N \dot{S} F],\left[\dot{R}_{s}\right]$, and $\left[R_{s}^{\prime}\right]$ are closely related to each other because the interaction terms with the reaction rates $k_{O}\left(\left[\mathrm{R}_{\mathrm{s}}{ }^{\prime}\right]\right)$ and $k_{4}\left(\left[\mathrm{R}_{\mathrm{s}}\right]\right)$ occur in all three ordinary differential equations describing the reaction kinetics. Therefore, these three differential equations can be reduced to a single differential equation, e.g., in the concentration [R's]. Now, the properties of the dynamical system can be discussed by hands of the production and decay terms of $R^{\prime}$.

The kinetics $k_{O}\left(\left[\mathrm{R}_{\mathrm{s}}{ }^{\prime}\right]\right)$ and $k_{4}\left(\left[\mathrm{R}_{\mathrm{s}}\right]\right)$ resulting from the polymerization of $R_{s}^{\prime}$ and $R_{s}$, respectively, have an S-shape and a self-excitation of each $R_{S}$, and of $R_{s}$. Both self-excitations are in competition to each other. Exemplary kinetics are given in Figure 2. The kinks are chosen for a better visibility of the interaction behavior in Figure 3 . The qualitative behavior is conserved for more realistic smooth S-shaped kinetics. Under standard levels of $\mathrm{P}_{\mathrm{NSF}}$, we find five stationary points, three stable stationary points separated by two unstable points (Figure 3, left panel). The stable stationary point with a low concentration of $R_{s}^{\prime}$ is associated with LTD, and the stable stationary point with a high concentration of $R_{s}^{\prime}$ is associated with LTP because the concentration of $R_{s}^{\prime}$ is closely related to the occurrence of AMPA homomers in the membrane. The stable stationary points stand for an active synapse which is not yet in LTD or LTP.

A more detailed analysis of the system of reaction kinetics works as follows: Stationary points are characterized by vanishing time derivatives of [NSF], $\left[\mathrm{R}_{\mathrm{S}}\right]$, and $\left[R^{\prime}\right.$ s]. As mentioned in (Langemann et al., 2008), all three kinetic equations contain the same interaction term between $R_{S}$ and NSF. Hence, in the stationary case, we get the complementary relation

$$
p_{N S F}-z_{N S F}[N S F]=p_{R_{s}}-z_{R_{s}}\left[R_{s}\right]=z_{R_{s}^{\prime}}\left[R_{s}^{\prime}\right]
$$

leading to the relations

$$
\left[R_{s}\right]=\frac{p_{R_{s}}-z_{R_{s}^{\prime}}\left[R_{s}^{\prime}\right]}{z_{R_{s}}} \text { and }[N S F]=\frac{p_{N S F}-z_{R_{s}^{\prime}}\left[R_{s}^{\prime}\right]}{z_{N S F}}
$$

in every stationary state of the synaptic system. We insert these relations in the last of the three kinetic equations, again for the stationary case, and we find 

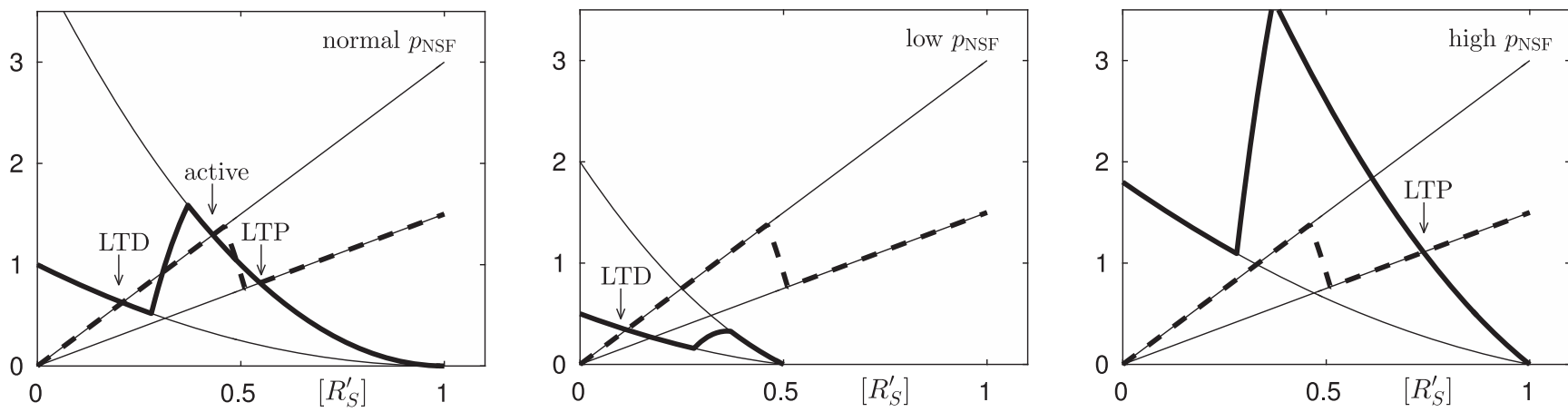

Figure 3. The number of stable stationary points depends on the NSF production rate. Left, With normal NSF production rates ( $\mathrm{p}_{\mathrm{NSF}}$ ), we find five stationary points, three stable stationary points (active, LTD, and LTP) separated by two unstable points. Middle, A low NSF production rate $\left(\mathrm{p}_{\mathrm{NSF}}\right)$ shifts the production and the decay term of $\mathrm{R}_{\mathrm{s}}$ so that only the stable stationary points remains which belongs to LTD. Right, A high NSF production rate $\left(\mathrm{p}_{\mathrm{NSF}}\right)$ drives the system into the only other stable stationary point which belongs to LTP.

$$
0=\frac{-\left(z_{R^{\prime} S}+k_{4}\right)\left[R^{\prime}{ }_{S}\right]}{\mathrm{D}}+\frac{k_{0} \frac{p_{R_{S}}-z_{R^{\prime} S}\left[R^{\prime}{ }_{S}\right]}{z_{R_{S}}} \cdot \frac{p_{N S F}-z_{R^{\prime} S}\left[R^{\prime}{ }_{S}\right]}{z_{N S F}}}{\mathrm{P}}
$$

which is an algebraic relation in only one variable, namely in $\left[R_{S}^{\prime}\right]$. The decay term $D$, which is always negative, and the positive production term $\mathrm{P}$ are equilibrated in every stationary point. They are shown in Figure 3 as blades of the scissors.

A standard concentration of NSF (Fig. 3, middle panel) leads to a middle intensity of the production term, and due to the S-shape of the self-activation curve, we get five stationary points. Three of them are stable, and they are activated with the LTD equilibrium, the active middle state and the LTP equilibrium. A transition of the system from one state into another is not immediately reversed and therefore, it means synaptic plasticity. Such a transition is mediated by a high or low NSF concentration over a time interval. A high production of NSF increases the blade standing for the production term, and only LTP persists as stable equilibrium (Fig. 3, right panel). Therefore, a temporarily increase of the NSF-production moves the system into LTP. Analogously, a temporarily decrease of the NSF-production decreases the production term $\mathrm{P}$, and only the LTD equilibrium survives.

A temporarily decreased level of $\mathrm{p}_{\mathrm{NSF}}$ shifts the production and the decay term of $R^{\prime}$ s so that only the stable stationary point remains, which belongs to LTD, and the relatively fast reaction system tends to this equilibrium (Fig. 3, middle panel). After a consequent re-increase of the $\mathrm{p}_{\mathrm{NSF}}$-level, the system slowly moves into the LTD equilibrium. Vice versa, a temporarily increased level of $\mathrm{p}_{\mathrm{NSF}}$ drives the system into LTP (Fig. 3, right panel). In this way, the plasticity behavior of a synapse can be traced back to reaction kinetics of simple biochemical reactions without any memory tag or unknown mechanism. Here, this core model is extended by the influence of stress hormones and by the impact of signal coincidence as discussed in the following paragraph.

\section{Model hierarchy}

The presented extension of the model from Langemann et al. (2008) concerns the influence of stress and the coincidence of the incoming signals on LTP or LTD, respectively, and lets the core model of the synaptic plasticity unchanged. The core model and the extension can be regarded as two steps of modeling with sequential interaction.

The first modeling step transforms the input quantities stress, described by the cortisol rate, and the coincidence of the signals, into the output rates of MR, GR, proBDNF, and mBDNF and thus the amount of active TrkB, p75, NSF, and $R_{S}$. Their concentrations enter the second modeling step, which is just the original core model.

On the one hand, the entire model presented here is a model extension, which allows to discuss the influence of stress and the coincidence of the incoming signals. On the other hand, the original core model is an independent sub-model in the entire model, and the entire model inherits the properties of the core model. This is the reason why, we refer for all discussion of the plasticity behavior itself to (Langemann et al., 2008).

\section{Results}

Our simulations show that correlated pre/postsynaptic activity leads to increased LTP at low cortisol concentrations (Fig. 4A). In contrast, correlated pre/postsynaptic activity leads to suppressed LTP in the presence of high cortisol concentrations (Fig. 4B). These results are in agreement with experiments comparing LTP in stressed and nonstressed animals using high-frequency stimulation, which is regarded to induce correlated pre/postsynaptic activity (Maggio and Segal, 2007). Our simulations also show that correlated pre/postsynaptic activity does not lead to LTP when glucocorticoids are absent (Fig. 4C). These results are in agreement with experimental evidence showing that the LTP induced by high-frequency stimulation was blunted when MR antagonists were added to high doses of glucocorticoids (Maggio and Segal, 2007). Thus, in case of correlated pre/postsynaptic activity, LTP shows a bell-shaped dependency on glucocorticoids: enhanced 
A
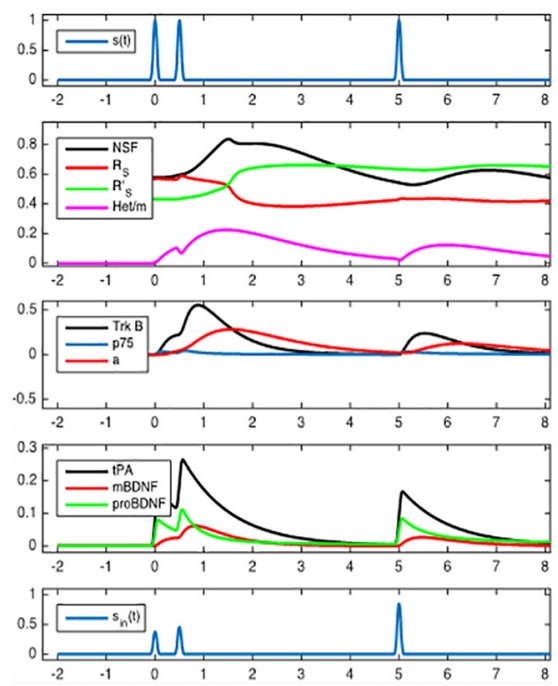

B
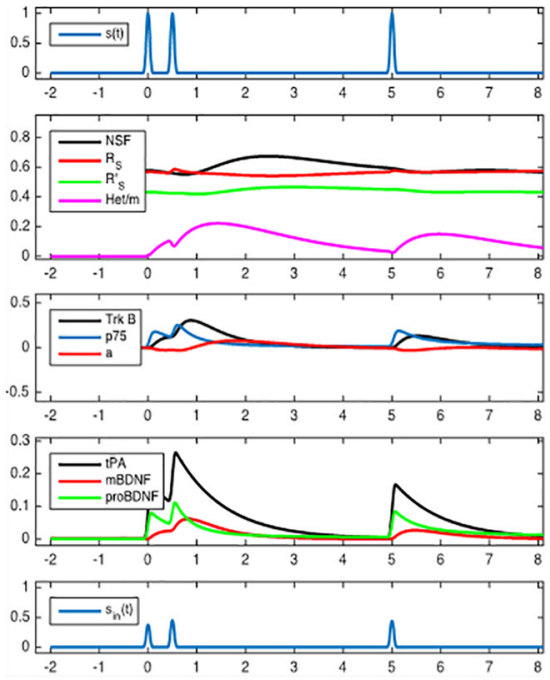

C
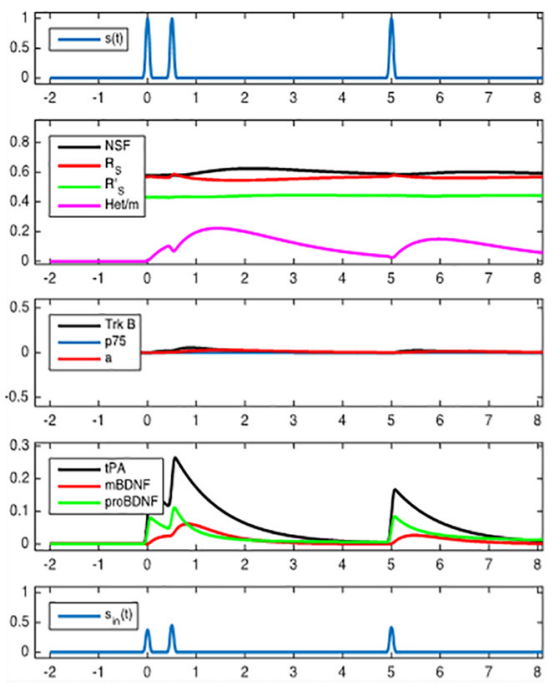

Figure 4. Simulation of correlated pre-/postsynaptic activity at three levels of cortisol concentrations. $\boldsymbol{A}$, Low cortisol. With correlated activity, mBDNF concentrations rise (4th panel, red curve). At low cortisol concentrations, the number of TrkB receptors is high. When high mBDNF concentrations meet a high number of TrkB receptors, TrkB signaling is enhanced (3rd panel, black curve). Consequently, protein production ( $R_{s}$ and NSF) increases (3rd panel, red curve). As a result, the probability that NSF will bind to $R_{s}$ increases, so that the activated form $R_{s}$ ' will prevail (2nd panel, the green curve becomes higher than the red curve). Thus, these simulations show that low cortisol concentrations combined with correlated pre-/postsynaptic activity produce a full-magnitude LTP of approximately double size as compared to baseline (5th panel; increased excitatory postsynaptic potentials at time 5, interpreted as hours). Comparison with experimental data, In nonstressed animals, high-frequency stimulation enhanced LTP by a factor of 1.69 compared to baseline (Maggio and Segal, 2007). B, High cortisol. With correlated activity, mBDNF concentrations rise (4th panel, red curve). At high cortisol concentrations, the number of TrkB receptors is low and the number of p75 receptors is high. When high mBDNF concentrations meet a small number of TrkB receptors, TrkB signaling is weak (3rd panel, black curve). Consequently, protein production ( $R_{s}$ and NSF) is only modestly increased (3rd panel, red curve). As a result, the probability that NSF will bind to $R_{s}$ is only modestly increased, so that the nonactivated form $R_{s}$ will prevail (2nd panel, the green curve remains lower than the red curve). Thus, these simulations show that high cortisol concentrations combined with correlated pre-/postsynaptic activity enhanced LTP only slightly (5th panel at time 5; compare Fig. 1). Comparison with experimental data, In stressed animals, high-frequency stimulation enhanced LTP by a factor of 1.42 only (Maggio and Segal, 2007). C, No cortisol. With correlated activity, mBDNF concentrations rise (4th panel, red curve). However, without cortisol, the number of TrkB receptors is low, and therefore TrkB signaling is almost absent (3rd panel, black curve). Consequently, protein production ( $R_{s}$ and NSF) is unaltered (3rd panel, red curve). Thus, these simulations show that in the absence of cortisol effects, correlated pre-/postsynaptic activity has changed the LTP only marginally (5th panel). Comparison with experimental data, When glucocorticoids were combined with MR antagonists, high-frequency stimulation enhanced LTP by a factor of 1.36 only (Maggio and Segal, 2007).

LTP occurs at low (normal) glucocorticoid concentrations, while high and very low glucocorticoid concentrations lead to suppressed LTP. The bell-shaped dependency of LTP probability on glucocorticoids has been often reported (Diamond et al., 1992; Pavlides et al., 1994, 1996; Joëls, 2006).

Furthermore, our simulations show that noncorrelated pre/postsynaptic activity leads to LTD at low cortisol concentrations (Fig. 5A). In contrast, at high cortisol concentrations, noncorrelated pre/postsynaptic activity enhanced LTD (Fig. 5B). These results are in agreement with the experimental evidence comparing LTD in stressed and nonstressed animals using low-frequency stimulation, which is regarded to induce only weakly correlated activity between the pre- and the postsynaptic neuron (Maggio and Segal, 2009). Our simulations also show that noncorrelated pre/postsynaptic activity does not lead to LTD in the absence of glucocorticoids (Fig. 5C). These results are in agreement with experimental evidence showing that noncorrelated pre/postsynaptic activity does not lead to LTD in the presence of MR and GR antagonists (Maggio and Segal, 2009). Thus, in the case of noncorrelated pre/postsynaptic activity LTD is most pronounced in the presence of high glucocorticoid concentrations, while LTD is suppressed at low (normal) or very low glucocorticoid concentrations.

We performed additional simulations to analyze whether the insertion of AMPA receptor heteromers into the postsynaptic density is indispensable for the development of LTP and LTD. In these simulations, the model parameter $k 11$, which describes the catalytic reaction for the transfer of $R_{S} R_{L}$ heteromers into the membrane, was set to zero. This means that in the simulated process the transfer of AMPA receptor heteromers into the membrane is prevented. These simulations (Figs. 6,7 ) show only marginal deviations from the results obtained before (Figs. 4, 5). Thus, our previously published core model consisted of a redundant model component, i.e., the transfer of AMPA receptor heteromers into the membrane. These results are in agreement with experimental evidence showing 
A
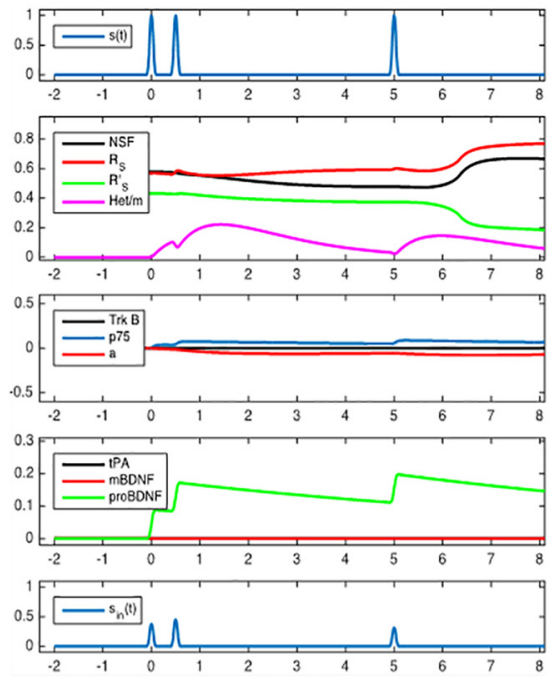

B
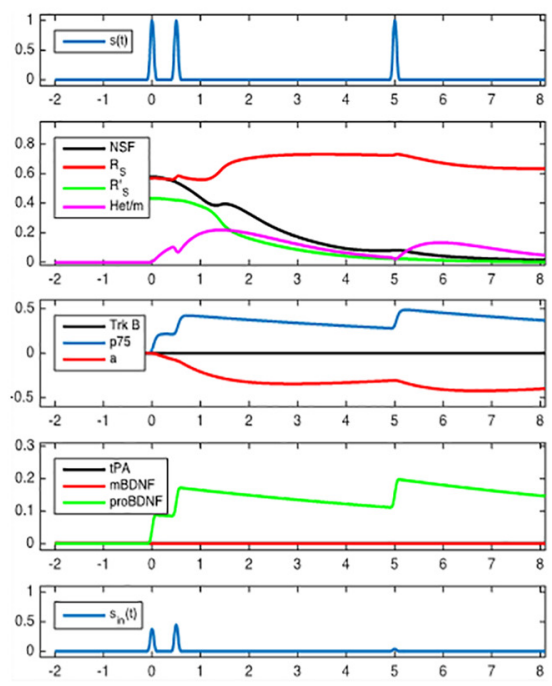

C
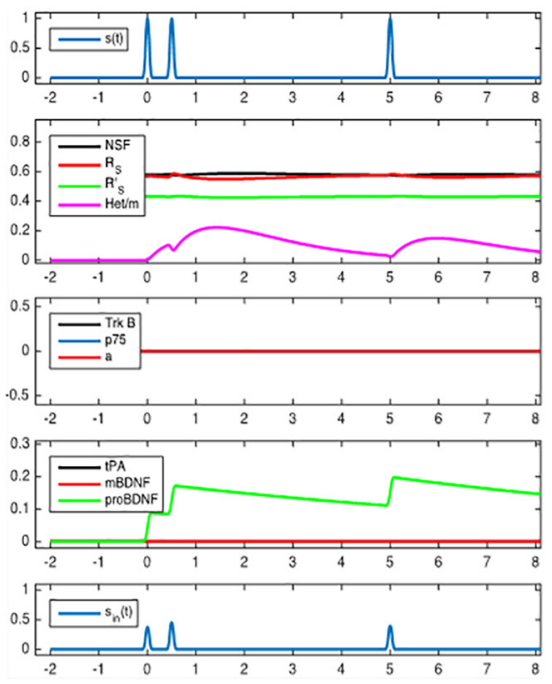

Figure 5. Simulation of noncorrelated pre-/postsynaptic activity at three levels of cortisol concentrations. $\boldsymbol{A}$, Low cortisol. With noncorrelated activity, proBDNF concentrations rise (4th panel, green curve). At low cortisol concentrations, the number of p75 receptors is low. When high proBDNF concentrations meet a low number of p75 receptors, p75 signaling is only modestly enhanced (3rd panel, blue curve). Consequently, protein production $\left(R_{s}\right.$ and NSF) decreases (3rd panel, red curve). As a result, the probability that NSF will bind to $R_{s}$ decreases, so that the nonactivated form $R_{s}$ will increase (2nd panel, the red curve becomes even higher than the green curve). Thus, these simulations show that low cortisol concentrations combined with noncorrelated pre-/postsynaptic activity produce a small LTD only (5th panel; decreased excitatory postsynaptic potentials at hour 5). Comparison with experimental data, In nonstressed animals, low-frequency stimulation evoked LTD amounting to 85\% of baseline level line (Maggio and Segal, 2009). B, High cortisol. With noncorrelated activity, proBDNF concentrations rise (4th panel, green curve). At high cortisol concentrations, the number of p75 receptors is high too. When high proBDNF concentrations meet a high number of p75 receptors, p75 signaling is strongly enhanced (3rd panel, blue curve). Consequently, protein production $\left(R_{s}\right.$ and NSF) is markedly decreased (3rd panel, red curve). As a result, the probability that NSF will bind to $R_{s}$ also markedly decreases, so that the nonactivated form $R_{s}$ will become excessively high (2nd panel, the red curve significantly exceeds the green curve). Thus, these simulations show that high cortisol concentrations combined with noncorrelated pre-/postsynaptic activity produce a marked LTD, which is less than half the baseline level (5th panel; compare panel $A$ ). Comparison with experimental data, In stressed animals, low-frequency stimulation produced an LTD amounting to only $49 \%$ of the baseline level line (Maggio and Segal, 2009). $\boldsymbol{C}$, No cortisol. With noncorrelated activity, proBDNF concentrations rise (4th panel, green curve). Without cortisol, the number of p75 receptors is very low, and therefore, p75 signaling is almost absent (3rd panel; black curve, which is covered by the red curve). Consequently, protein production $\left(\mathrm{R}_{\mathrm{s}}\right.$ and NSF) is unaltered (3rd panel, red curve). Thus, these simulations show that in the absence of cortisol effects, noncorrelated pre-/postsynaptic activity has produced a small LTD only (5th panel). Comparison with experimental data, When nonstressed animals were treated with the combination of MR and GR antagonists, low-frequency stimulation produced a LTD which was only $83 \%$ of the baseline (Maggio and Segal, 2009).

that the transfer of AMPA receptor heteromers into the membrane is dispensable for inducing and maintain LTP (Granger et al., 2013).

\section{Discussion}

Our modeling of synaptic plasticity shows that LTP occurs, if there is correlated activity between the pre- and postsynaptic neuron and glucocorticoids are in an optimal range (low normal concentrations). Optimal glucocorticoid concentrations maximize the number of TrkB receptors expressed on the postsynaptic density and correlated pre/postsynaptic activity maximizes the concentrations of mBDNF in the synaptic cleft. This association of the ligand BDNF and its TrkB receptors specifies a logical AND operation. In all other cases, when glucocorticoid concentrations are not in the optimal range or pre-/postsynaptic activity is only weakly correlated, LTP is attenuated or even LTD occurs. The results of our simulations are in agreement with the experimental evidence (Maggio and Segal, 2007, 2009).
Many biophysical models of synaptic plasticity exist, but, to the best of our knowledge, none of them has dealt with the question how glucocorticoids modulate the occurrence of LTP or LTD. The earlier of these models focused on the early phase of LTP and LTD (which is independent of protein synthesis). They were based on the assumption that LTP depends on calcium influx through NMDA-Rs (Gamble and Koch, 1987; Holmes and Levy, 1990; Zador et al., 1990). John Lisman was the one who constructed the first influential model of signal transduction pathways associated with synaptic plasticity (Lisman, 1989). His crucial question was how the same molecule, calcium, can trigger both LTP and LTD. Lisman proposed that moderate calcium levels primarily activate phosphatases that dephosphorylate $\mathrm{Ca}^{++} / \mathrm{CaMKII}$, while high calcium levels promote the phosphorylation of CaMKII, and thus explain bidirectional synaptic plasticity. This hypothesis has subsequently received significant experimental support. The model of Lisman and the subsequent models of 

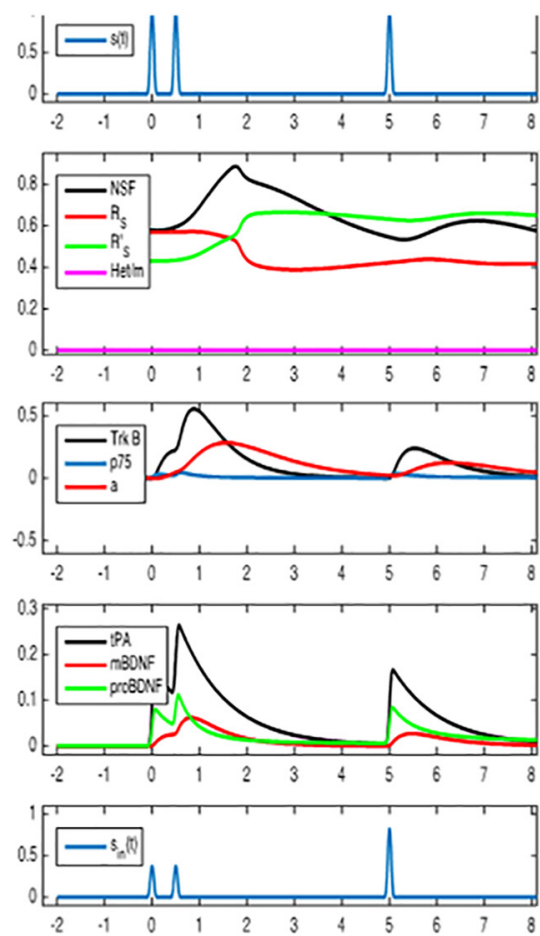
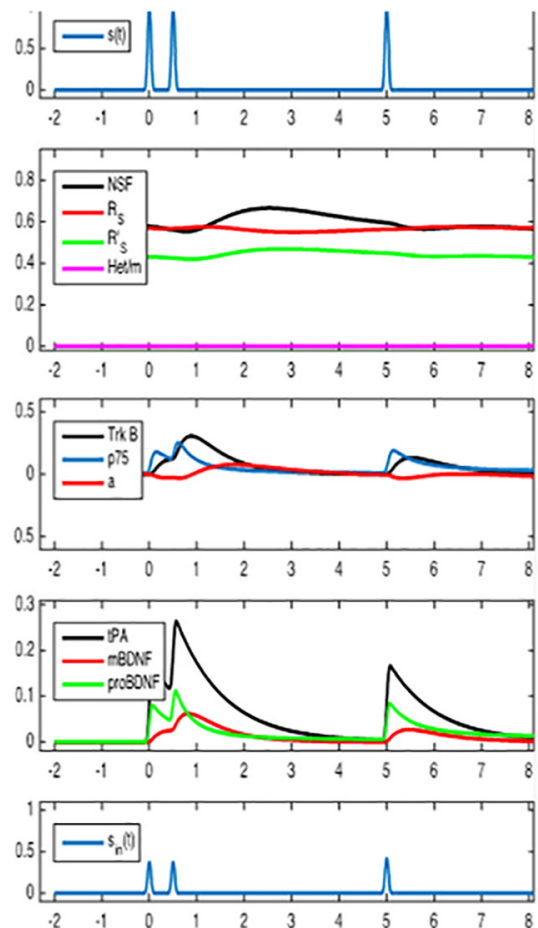
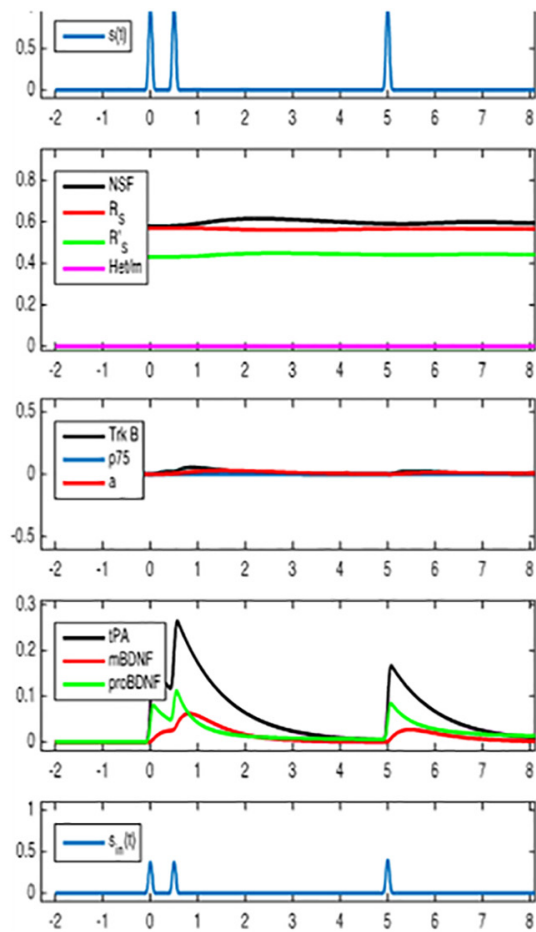

Figure 6. Simulations of correlated pre-/postsynaptic activity at three levels of cortisol concentrations when the insertion of long-tailed AMPA receptor subunits into the membrane is prevented. Low, high, and very low cortisol concentrations are shown in the left, middle, and right panels, respectively. The simulations depicted here do only marginally deviate from the simulations obtained when the insertion of long-tailed AMPA receptor subunits into the membrane is not prevented (compare Fig. $4 A-C$ ).
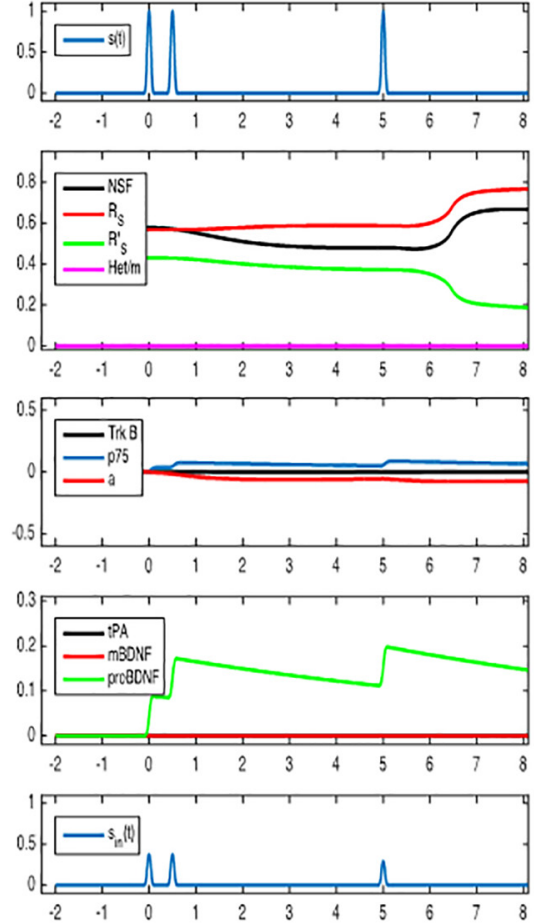
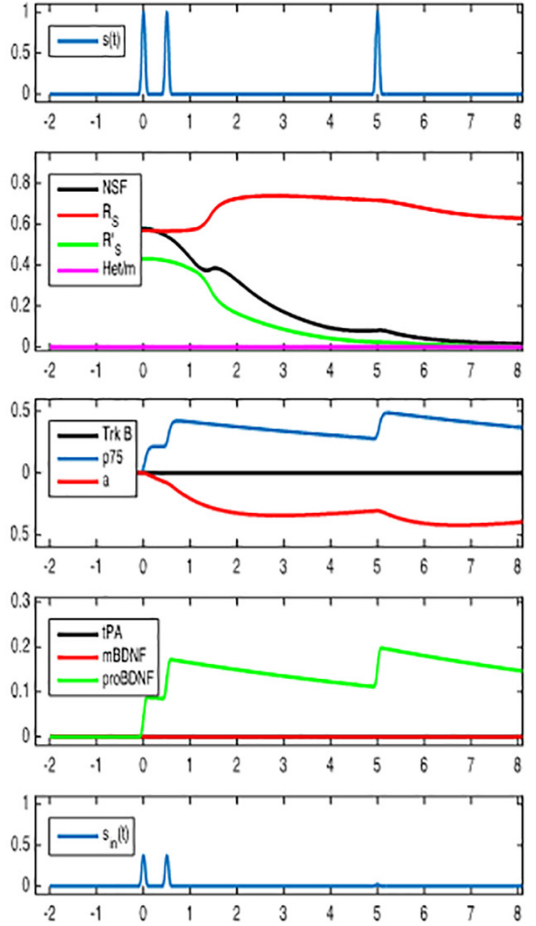
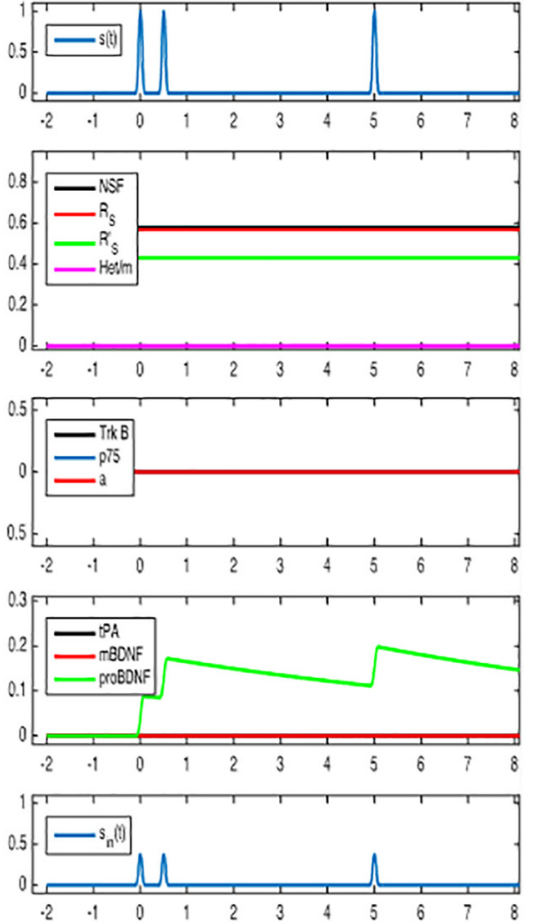

Figure 7. Simulations of noncorrelated pre-/postsynaptic activity at three levels of cortisol concentrations when the insertion of long-tailed AMPA receptor subunits into the membrane is prevented. Low, high, and very low cortisol concentrations are shown in the left, middle, and right panels, respectively. The simulations depicted here do only marginally deviate from the simulations obtained when the insertion of long-tailed AMPA receptor subunits into the membrane is not prevented (compare Fig. $5 A-C$ ). 
Castellani displayed a limited number of components of the signal transduction path (Lisman, 1989; Castellani et al., 2001, 2005). Bhalla and co-workers extended these basic models by including additional components (Ajay and Bhalla, 2004). Other models of the induction of synaptic plasticity were either explicitly or implicitly based on the original hypothesis of Lisman (Karmarkar and Buonomano, 2002; Shouval et al., 2002). All of these former models focused on joint pre- and postsynaptic activity, but neglected the potential role of neuromodulators.

More recent models focused on the late phase of LTP and LTD, which is dependent on protein synthesis. Some of these models have included the role of neuromodulators such as acetylcholine, noradrenaline, serotonin and dopamine (Frémaux and Gerstner, 2016), but not glucocorticoids. In the current work, we refer to data that show how glucocorticoids affect the protein synthesis in the late phase of LTP and LTD. Although the key mechanisms of the early and late phase of synaptic plasticity are different, there are structural similarities in the interaction of these mechanisms. These formal similarities become evident when comparing the model of Lisman (as described above) with ours. In our model, moderate calcium levels favor the presence of proBDNF in the synaptic cleft, thereby reducing postsynaptic protein production, while high calcium levels favor the presence of mBDNF, thereby increasing postsynaptic protein production, thus accounting for bidirectional synaptic plasticity. In view of these formal similarities between the model of Lisman and our model, it is not surprising that the predictions of both models were similar. These formal similarities suggest that the basic regulatory principle that Lisman has discovered in the early phase of LTP and LTD is also detectable in the late phase. Focusing on the mechanisms of synaptic plasticity that regulate protein production put us in a position to model the neuromodulatory effects of glucocorticoids.

The model presented here may allow for a deeper understanding of the question when and how LTP or LTD occur during stress. According to a novel framework about "uncertainty and stress," the brain consolidates an "internal model of the world' only in the absence of "expected surprise," i.e. uncertainty (Peters et al., 2017). According to this concept, the brain minimizes its prediction errors, i.e., the differences between an organism's predictions about its sensory inputs (embodied in its internal model of the world) and the sensations it actually encounters (Friston, 2010). The absence of uncertainty, which leads to lownormal glucocorticoid concentrations, indicates that the current internal model of the world makes accurate predictions, and thus it would make sense to consolidate this model through memory formation. Underlying such a consolidation is, among other things, e.g., dendritic spine remodeling, dendritic arbor shaping (Liston et al., 2013; Ikeda et al., 2015), the process of LTP (Joëls, 2006). In contrast, if the internal model of the world is not suitable for making accurate predictions, uncertainty will increase, as will glucocorticoid concentrations. In this case, the current internal model of the world is deconstructed and the underlying mechanisms include, among other things, e.g., dendritic arbor shrinkage (McEwen and Morrison, 2013), the process of LTD. Thus, consolidation of the internal model of the world is promoted at optimal (low normal) glucocorticoid concentrations, which indicate the absence of uncertainty or stress; in contrast, the reformation of the internal model of the world is promoted at excess glucocorticoid concentrations, which favor LTD (Peters et al., 2017). In all, our mathematical model of synaptic plasticity may provide a mechanistic explanation how the brain makes appropriate updates of its model of the world.

Our simulation study may allow predictions for future research. Learning (i.e., consolidation of memory) occurs, if the brain's prediction errors are minimized (Friston, 2005). Accordingly, our model of synaptic plasticity predicts that "prediction-error minimization" manifests itself through maximization of the number of mBDNF molecules in the synaptic cleft, maximization of the number of TrkB receptors expressed at the postsynaptic density, maximization of postsynaptic TrkB signaling, maximization of the number of activated short-tailed AMPA receptor subunits within the cytosolic pool, and finally through maximization of LTP probability. If we consider memory consolidation as such an "optimization problem," we will be able to design future experiments that could test the following predictions of our model: experimental interventions that systematically alter the correlation between pre- and postsynaptic activity and glucocorticoid concentrations will lead to a maximum LTP probability if and only if the synaptic mBDNF concentrations and TrkB receptors expressed at the postsynaptic density are maximal. Similarly, such interventions will lead to a maximum LTD probability, if the synaptic proBDNF concentrations and the density of the postsynaptically expressed p75 receptors are maximal.

The model presented here had already made a prediction that has been confirmed experimentally four years ago (Granger et al., 2013). Almost a decade ago, we have published the core model, which described AMPA receptor trafficking (Langemann et al., 2008). That core model was based on experimental evidence showing that regulated addition of GluA1-GluA2 and continuous replacement of GluA2-GluA3 containing synaptic AMPA receptors provide the mechanism of how surface receptor number is established and maintained (Shi et al., 2001). This experimental work was the basis of a widely-accepted view of how LTP is induced and maintained. In 2013, however, this view was challenged by experiments showing no requirement for the GluA1 C-tail for LTP (Granger et al., 2013). The GluA1 C-tail plays a key role in driving AMPA receptor heteromers into the synaptic density (Henley and Wilkinson, 2016). Because we had included these kinds of reactions in our core model (Langemann et al., 2008), we now had the opportunity for post hoc testing as to whether this model component was dispensable for predicting experimental evidences. To address this question, we deleted the model component that described the movement of AMPA receptor heteromers into the synaptic density as well as their removal from the synaptic density. In the current paper, we could show that after 
A

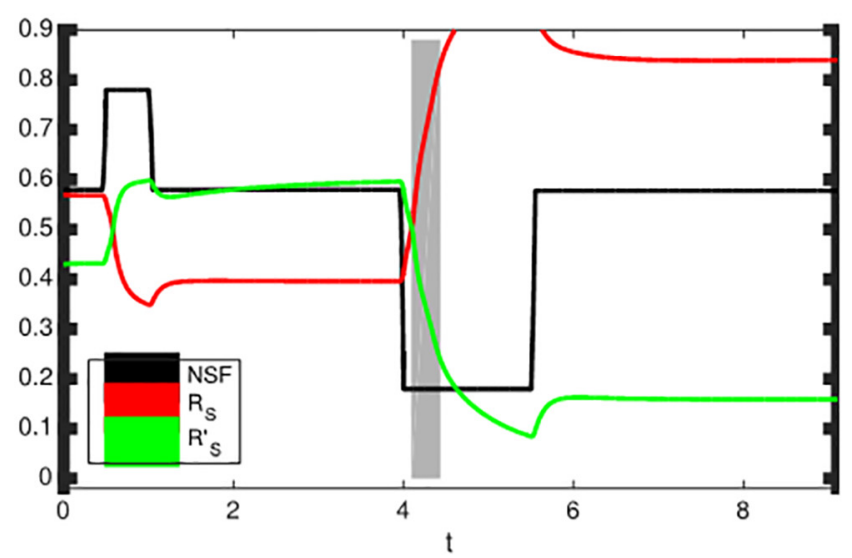

B

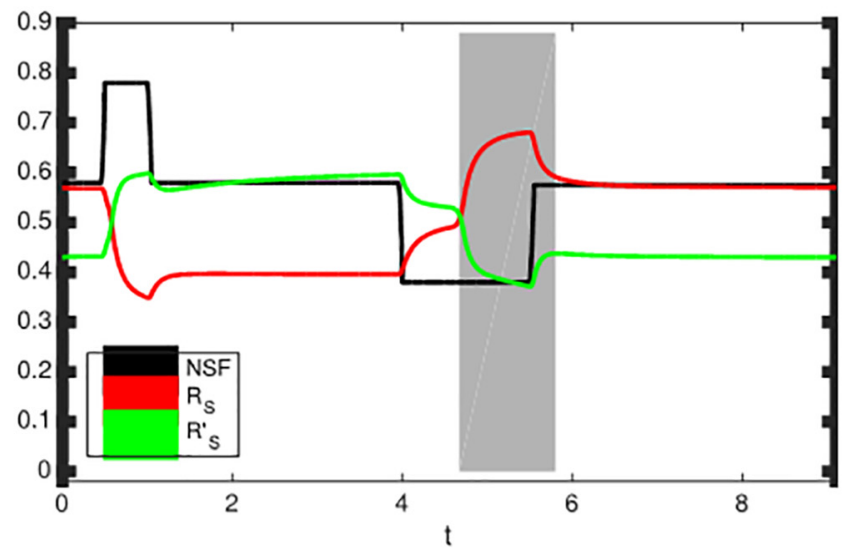

Figure 8. Model predictions on the likelihood of an LTP-to-LTD conversion. The simulations were performed to make predictions that could be tested in future experiments. An initial interventional increase in NSF production generates LTP $(t<1)$. Left, A strong subsequent interventional decrease of NSF is likely to convert LTP into LTD. There is an underproportionally short time interval (gray bar) not leading to LTD. Right, A small subsequent interventional decrease in NSF increases the likelihood that the synapse will not transition into LTD but into the middle active state. There is an overproportionally long time interval (gray bar) not leading to LTD.

removal of this model component, our simulation results were still in agreement with the experimental evidence (Figs. 6, 7). Although our core model was based on older experimental evidence, it still was capable of predicting novel evidence that had appeared later (Granger et al., 2013).

The model presented here confines itself to describing LTP and LTD occurring at the postsynaptic sites of glutamatergic synapses. Of course, there are multiple phenomenological and mechanistic forms of LTP and LTD, which occur pre- and postsynaptically at glutamatergic and GABAergic synapses (Castillo, 2012; Yang and Calakos, 2013). At GABAergic synapses, postsynaptic GABA receptors in cooperation with VDCCs act as coincidence detectors (Gaiarsa et al., 2002; Kuczewski et al., 2010, 2011). GABA released from the presynaptic terminal activates postsynaptic $\mathrm{GABA}_{\mathrm{B}}$ receptors, and backpropagating APs activate the VDCCs. On activation of the $\mathrm{GABA}_{\mathrm{B}}-\mathrm{VDCC}$ complex, BDNF concentrations increase in the synaptic cleft. BDNF can also activate TrkB receptors located on presynaptic glutamatergic and GABAergic terminals (Tyler and Pozzo-Miller, 2001; Gubellini et al., 2005; Inagaki et al., 2008). At several glutamatergic and GABAergic synapses, neuronal activity can trigger enduring increases or decreases in neurotransmitter release, thereby producing LTP or LTD of synaptic strength, respectively. According to the same basic principles as presented in the current work, a future modeling of the "influence of stress on synaptic plasticity" is conceivable: It extends the present model by implementing the BDNF/TrkB system at presynaptic terminals and GABAergic synapses.

VDCCs play a role in other forms of LTP and LTD. VDCC-dependent LTP is enhanced by the same dosage of corticosterone that impairs NMDA-R-dependent LTP (Krugers et al., 2005). This species of LTP is found in the amygdala where it is believed to underlie the formation of fear memories (Blair et al., 2001). In emotional memory formation, membrane-bound MR play a crucial role in the induction of LTP (Maggio and Segal, 2012). VDCCs also constitute key mechanisms in associative LTD in the hippocampus, a form of spike time-dependent synaptic plasticity that is induced by the asynchronous pairing of postsynaptic action potentials and EPSPs (Niehusmann et al., 2010). This process is regulated by free calcium at the level of PKC and PICK1, both of which are calcium dependent. The sources of the relatively low calcium increase in LTD are VDCCs and intracellular calcium stores. Action potentials open VDCCs. Hence, in a situation where an action potential precedes the EPSP, calcium will be present at the time that glutamate activates postsynaptically the metabotropic glutamate receptor-dependent pathway (Niehusmann et al., 2010). The role of BDNF in all of these forms of NMDA-independent forms of LTP and LTD is less certain. The findings of Aarse et al. (2016) suggest that in behaving animal, the contribution of BDNF to information encoding in the form of synaptic plasticity is graded and highly dependent on experience-related factors such as the stimulus pattern and the history of synaptic experience. Nonetheless, the model presented in the current paper is limited to NMDA-dependent plasticity.

Model-derived hypotheses should be testable by future experiments. Experimental interventions that would alter the NSF production could provide further evidence to support the proposed model with three stable stationary points representing LTP, LTD and the middle active state. A high production of NSF is predicted to drive synapses in LTP. After a subsequent reduction in NSF production (which NSF returns to the previous level), LTP is predicted to persist, and an increased amount of AMPA homomers is expected to be found in the postsynaptic density. Figure 8 shows such an initial interventional increase of NSF and the resulting changes in synapse, i.e., the transition from the middle active state to LTP (time interval before $t=$ 1). In case of a subsequent interventional reduction of NSF (at time $t=4$ ), the qualitative conceptual framework of the present study predicts two possible scenarios: Depending 
on the intensity of the subsequent NSF reduction, either LTD or the middle active state is obtained (Fig. $8 A, B$ ). A comparison may illustrate the situation: The system with three stable stationary points acts like a "skill game," in which a small ball has to be placed in different dimples. The middle active state has a small area of attraction, and it is expected that an external influence that results in a slow change makes it possible to find the middle equilibrium in the active state, but not a rapid change.

Figure $8 \mathrm{~A}$ shows a strong subsequent experimental reduction of NSF, and the system occupies the stationary stable point related to LTD, as discussed above. The simulation shows that a rather short time interval of a strong $\mathrm{P}_{\text {NSF }}$ reduction is sufficient to transfer the synaptic system into LTD. The gray bar indicates the length of the time interval during which the system does not move to LTD. The simulations show that there are only a few interval lengths that are not associated with LTD. These simulation results agree with the interpretation that a strong reduction of NSF leads to a rapid system change. Consequently, it is predicted that under such conditions the system will occupy the LTD equilibrium in most cases; it appears rather rare and only possible for short $\mathrm{P}_{\mathrm{NSF}}$ reductions that the system will not move into LTD.

In contrast, Figure $8 B$ shows a comparatively small subsequent experimental reduction of NSF. The simulations show that the system has an overproportionately large range of time interval lengths (marked by the gray bar) that is not associated with the LTD equilibrium. It is not fully clear whether there are additional mechanisms, which are not modeled here, preventing the system from falling back into the active state. But according to our model, a modest subsequent interventional reduction of NSF is less likely to cause LTD.

In all, the model-derived hypothesis that duration and intensity of a particular experimental intervention determine which of the three equilibrium states in the synaptic plasticity is occupied can be directly tested in future experiments. Such an approach could test the internals of the model presented here.

Reducing model complexity, while maintaining model accuracy, is always an important issue (Friston, 2010). As shown above, novel evidence helps to remove dispensable elements from a model without affecting the model's ability to make accurate predictions. According to Occam's razor the model is best when it makes accurate predictions with minimal complexity. Of course, we are aware that the process of synaptic plasticity involves a large number of different molecules. However, the question is whether all these mechanisms are necessary for predicting experimental results. With the model presented here we tried to keep the number of factors that affect LTP or LTD at a minimum. The complexity of the model presented here is relatively low, but the model components are sufficient to accurately predict the experimental results (Maggio and Segal, 2007, 2009).

In conclusion, our simulations may help to explain how glucocorticoids and pre/postsynaptic activity govern the occurrence of NMDA-R-dependent LTP or LTD. The joint mechanism in that process appears to be the interaction between BDNF and BDNF receptors. Full LTP occurs if glucocorticoids are in an optimal (low normal) range and activity between the pre- and postsynaptic neuron is highly correlated. During stress, however, high glucocorticoid levels suspend these learning processes. Our findings may provide a mechanistic basis for understanding how the brain controls learning under uncertainty.

\section{References}

Aarse J, Herlitze S, Manahan-Vaughan D (2016) The requirement of BDNF for hippocampal synaptic plasticity is experiencedependent. Hippocampus 26:739-751. CrossRef Medline

Ajay SM, Bhalla US (2004) A role for ERKII in synaptic pattern selectivity on the time-scale of minutes. Eur J Neurosci 20:26712680. CrossRef Medline

Arriza JL, Simerly RB, Swanson LW, Evans RM (1988) The neuronal mineralocorticoid receptor as a mediator of glucocorticoid response. Neuron 1:887-900. Medline

Bi G, Poo M (2001) Synaptic modification by correlated activity: Hebb's postulate revisited. Annu Rev Neurosci 24:139-166. CrossRef Medline

Blair HT, Schafe GE, Bauer EP, Rodrigues SM, LeDoux JE (2001) Synaptic plasticity in the lateral amygdala: a cellular hypothesis of fear conditioning. Learn Mem 8:229-242. CrossRef Medline

Castellani GC, Quinlan EM, Cooper LN, Shouval HZ (2001) A biophysical model of bidirectional synaptic plasticity: dependence on AMPA and NMDA receptors. Proc Natl Acad Sci USA 98:1277212777. CrossRef Medline

Castellani GC, Quinlan EM, Bersani F, Cooper LN, Shouval HZ (2005) A model of bidirectional synaptic plasticity: from signaling network to channel conductance. Learn Mem 12:423-432. CrossRef Medline

Castillo PE (2012) Presynaptic LTP and LTD of excitatory and inhibitory synapses. Cold Spring Harb Perspect Biol 4:a005728.

de Kloet ER, Vreugdenhil E, Oitzl MS, Joëls M (1998) Brain corticosteroid receptor balance in health and disease. Endocr Rev 19: 269-301. CrossRef Medline

Diamond DM, Bennett MC, Fleshner M, Rose GM (1992) Inverted-U relationship between the level of peripheral corticosterone and the magnitude of hippocampal primed burst potentiation. Hippocampus 2:421-430. CrossRef Medline

Esteban JA (2003) AMPA receptor trafficking: a road map for synaptic plasticity. Mol Interv 3:375-385. CrossRef Medline

Frémaux N, Gerstner W (2016) Neuromodulated spike-timingdependent plasticity, and theory of three-factor learning rules. Front Neural Circuits 9:85. CrossRef Medline

Friston K (2005) A theory of cortical responses. Philos Trans R Soc Lond B Biol Sci 360:815-836. CrossRef Medline

Friston K (2010) The free-energy principle: a unified brain theory? Nat Rev Neurosci 11:127-138. CrossRef Medline

Gaiarsa JL, Caillard O, Ben-Ari Y (2002) Long-term plasticity at GABAergic and glycinergic synapses: mechanisms and functional significance. Trends Neurosci 25:564-570. Medline

Gamble E, Koch C (1987) The dynamics of free calcium in dendritic spines in response to repetitive synaptic input. Science 236:13111315. Medline

Granger AJ, Shi Y, Lu W, Cerpas M, Nicoll RA (2013) LTP requires a reserve pool of glutamate receptors independent of subunit type. Nature 493:495-500. CrossRef Medline

Gualandris A, Jones TE, Strickland S, Tsirka SE (1996) Membrane depolarization induces calcium-dependent secretion of tissue plasminogen activator. J Neurosci 16:2220-2225. Medline

Gubellini P, Ben-Ari Y, Gaïarsa JL (2005) Endogenous neurotrophins are required for the induction of GABAergic long-term potentiation in the neonatal rat hippocampus. J Neurosci 25:5796-5802. CrossRef Medline 
Henley JM, Wilkinson KA (2016) Synaptic AMPA receptor composition in development, plasticity and disease. Nat Rev Neurosci 17:337-350. CrossRef Medline

Holmes WR, Levy WB (1990) Insights into associative long-term potentiation from computational models of NMDA receptormediated calcium influx and intracellular calcium concentration changes. J Neurophysiol 63:1148-1168. CrossRef Medline

Huang EJ, Reichardt LF (2003) TRK receptors: roles in neuronal signal transduction. Annu Rev Biochem 72:609-642. CrossRef Medline

Ikeda M, Hojo Y, Komatsuzaki Y, Okamoto M, Kato A, Takeda T, Kawato S (2015) Hippocampal spine changes across the sleepwake cycle: corticosterone and kinases. J Endocrinol 226:M13M27. CrossRef Medline

Inagaki $\mathrm{T}$, Begum $\mathrm{T}$, Reza $\mathrm{F}$, Horibe $\mathrm{S}$, Inaba M, Yoshimura $\mathrm{Y}$, Komatsu Y (2008) Brain-derived neurotrophic factor-mediated retrograde signaling required for the induction of long-term potentiation at inhibitory synapses of visual cortical pyramidal neurons. Neurosci Res 61:192-200. CrossRef Medline

Joëls M (2006) Corticosteroid effects in the brain: U-shape it. Trends Pharmacol Sci 27:244-250. CrossRef

Karmarkar UR, Buonomano DV (2002) A model of spike-timing dependent plasticity: one or two coincidence detectors? J Neurophysiol 88:507-513. CrossRef Medline

Krugers HJ, Alfarez DN, Karst H, Parashkouhi K, van GN, Joëls M (2005) Corticosterone shifts different forms of synaptic potentiation in opposite directions. Hippocampus 15:697-703. CrossRef

Kuczewski N, Porcher C, Gaiarsa JL (2010) Activity-dependent dendritic secretion of brain-derived neurotrophic factor modulates synaptic plasticity. Eur J Neurosci 32:1239-1244. CrossRef Medline

Kuczewski N, Fuchs C, Ferrand N, Jovanovic JN, Gaiarsa JL, Porcher C (2011) Mechanism of GABAB receptor-induced BDNF secretion and promotion of GABAA receptor membrane expression. J Neurochem 118:533-545. CrossRef Medline

Langemann D, Pellerin L, Peters A (2008) Making sense of AMPA receptor trafficking by modeling molecular mechanisms of synaptic plasticity. Brain Res 1207:60-72. CrossRef Medline

Lee R, Kermani P, Teng KK, Hempstead BL (2001) Regulation of cell survival by secreted proneurotrophins. Science 294:1945-1948. CrossRef Medline

Lisman $J$ (1989) A mechanism for the Hebb and the anti-Hebb processes underlying learning and memory. Proc Natl Acad Sci USA 86:9574-9578. Medline

Liston C, Cichon JM, Jeanneteau F, Jia Z, Chao MV, Gan WB (2013) Circadian glucocorticoid oscillations promote learning-dependent synapse formation and maintenance. Nat Neurosci 16:698-705. CrossRef Medline

Luscher C, Malenka RC (2012) NMDA receptor-dependent long-term potentiation and long-term depression (LTP/LTD). Cold Spring Harb Perspect Biol 4:a005710. CrossRef

Maggio N, Segal M (2007) Striking variations in corticosteroid modulation of long-term potentiation along the septotemporal axis of the hippocampus. J Neurosci 27:5757-5765. CrossRef Medline

Maggio N, Segal M (2009) Differential modulation of long-term depression by acute stress in the rat dorsal and ventral hippocampus. J Neurosci 29:8633-8638. CrossRef Medline

Maggio N, Segal M (2012) Steroid modulation of hippocampal plasticity: switching between cognitive and emotional memories. Front Cell Neurosci 6:12. CrossRef Medline

McEwen BS, Morrison JH (2013) The brain on stress: vulnerability and plasticity of the prefrontal cortex over the life course. Neuron 79:16-29. CrossRef Medline

Minichiello L, Korte M, Wolfer D, Kühn R, Unsicker K, Cestari V, Rossi-Arnaud C, Lipp HP, Bonhoeffer T, Klein R (1999) Essential role for TrkB receptors in hippocampus-mediated learning. Neuron 24:401-414. Medline

Miyashita T, Oda Y, Horiuchi J, Yin JC, Morimoto T, Saitoe M (2012) $\mathrm{Mg}(2+)$ block of Drosophila NMDA receptors is required for long- term memory formation and CREB-dependent gene expression. Neuron 74:887-898. CrossRef Medline

Narisawa-Saito M, Carnahan J, Araki K, Yamaguchi T, Nawa H (1999) Brain-derived neurotrophic factor regulates the expression of AMPA receptor proteins in neocortical neurons. Neuroscience 88:1009-1014. Medline

Niehusmann P, Seifert G, Clark K, Atas HC, Herpfer I, Fiebich B, Bischofberger J, Normann C (2010) Coincidence detection and stress modulation of spike time-dependent long-term depression in the hippocampus. J Neurosci 30:6225-6235. CrossRef Medline

Nishimune A, Isaac JT, Molnar E, Noel J, Nash SR, Tagaya M, Collingridge GL, Nakanishi S, Henley JM (1998) NSF binding to GluR2 regulates synaptic transmission. Neuron 21:87-97. Medline

Pang PT, Teng HK, Zaitsev E, Woo NT, Sakata K, Zhen S, Teng KK, Yung WH, Hempstead BL, Lu B (2004) Cleavage of proBDNF by tPA/plasmin is essential for long-term hippocampal plasticity. Science 306:487-491. CrossRef Medline

Pavlides C, Kimura A, Magariños AM, McEwen BS (1994) Type I adrenal steroid receptors prolong hippocampal long-term potentiation. Neuroreport 5:2673-2677. Medline

Pavlides C, Ogawa S, Kimura A, McEwen BS (1996) Role of adrenal steroid mineralocorticoid and glucocorticoid receptors in longterm potentiation in the CA1 field of hippocampal slices. Brain Res 738:229-235. Medline

Peters A, McEwen BS, Friston K (2017) Uncertainty and stress: why it causes diseases and how it is mastered by the brain. Prog Neurobiol 156:164-188. CrossRef Medline

Popoli M, Yan Z, McEwen BS, Sanacora G (2011) The stressed synapse: the impact of stress and glucocorticoids on glutamate transmission. Nat Rev Neurosci 13:22-37. CrossRef Medline

Quirarte GL, Roozendaal B, McGaugh JL (1997) Glucocorticoid enhancement of memory storage involves noradrenergic activation in the basolateral amygdala. Proc Natl Acad Sci USA 94:1404814053. Medline

Rösch H, Schweigreiter R, Bonhoeffer T, Barde YA, Korte M (2005) The neurotrophin receptor p75NTR modulates long-term depression and regulates the expression of AMPA receptor subunits in the hippocampus. Proc Natl Acad Sci USA 102:7362-7367. CrossRef Medline

Schaaf MJ, Hoetelmans RW, de Kloet ER, Vreugdenhil E (1997) Corticosterone regulates expression of BDNF and trkB but not NT-3 and trkC mRNA in the rat hippocampus. J Neurosci Res 48:334-341. CrossRef

Shi B, Mocchetti I (2000) Dexamethasone induces TrkA and p75NTR immunoreactivity in the cerebral cortex and hippocampus. Exp Neurol 162:257-267. CrossRef

Shi S, Hayashi Y, Esteban JA, Malinow R (2001) Subunit-specific rules governing AMPA receptor trafficking to synapses in hippocampal pyramidal neurons. Cell 105:331-343. Medline

Shouval HZ, Bear MF, Cooper LN (2002) A unified model of NMDA receptor-dependent bidirectional synaptic plasticity. Proc Natl Acad Sci USA 99:10831-10836. CrossRef Medline

Stranahan AM, Arumugam TV, Cutler RG, Lee K, Egan JM, Mattson MP (2008) Diabetes impairs hippocampal function through glucocorticoid-mediated effects on new and mature neurons. Nat Neurosci 11:309-317. CrossRef Medline

Stranahan AM, Arumugam TV, Lee K, Mattson MP (2010) Mineralocorticoid receptor activation restores medial perforant path LTP in diabetic rats. Synapse 64:528-532. CrossRef Medline

Stranahan AM, Arumugam TV, Mattson MP (2011) Lowering corticosterone levels reinstates hippocampal brain-derived neurotropic factor and Trkb expression without influencing deficits in hypothalamic brain-derived neurotropic factor expression in leptin receptor-deficient mice. Neuroendocrinology 93:58-64. CrossRef Medline

Tyler WJ, Pozzo-Miller LD (2001) BDNF enhances quantal neurotransmitter release and increases the number of docked vesicles 
at the active zones of hippocampal excitatory synapses. J Neurosci 21:4249-4258. Medline

Woo NH, Teng HK, Siao CJ, Chiaruttini C, Pang PT, Milner TA, Hempstead BL, Lu B (2005) Activation of p75NTR by proBDNF facilitates hippocampal long-term depression. Nat Neurosci 8:1069-1077. CrossRef Medline

Wosiski-Kuhn M, Erion JR, Gomez-Sanchez EP, Gomez-Sanchez CE, Stranahan AM (2014) Glucocorticoid receptor activation impairs hippocampal plasticity by suppressing BDNF expression in obese mice. Psychoneuroendocrinology 42:165-177. CrossRef Medline

Yang Y, Calakos N (2013) Presynaptic long-term plasticity. Front Synaptic Neurosci 5:8. CrossRef Medline

Zador A, Koch C, Brown TH (1990) Biophysical model of a Hebbian synapse. Proc Natl Acad Sci USA 87:6718-6722. Medline

Zhang X, Poo MM (2002) Localized synaptic potentiation by BDNF requires local protein synthesis in the developing axon. Neuron 36:675-688. Medline 